\title{
Rehabilitation of a Northern Elephant Seal Pup (Mirounga angustirostris) with Kyphosis
}

\author{
Lauren Mulreany, DVM Candidate \\ California Wildlife CENTER \\ Calabassas, California
}

\begin{abstract}
A juvenile Northern elephant seal (Mirounga angustirostris) with kyphosis was rehabilitated and released. Radiographs revealed a divergence of the thoracic vertebrae by an angle of 66.72 degrees. The pup was treated with supportive care and released back into the wild. Diagnostic techniques of marine mammal skeletal abnormalities and their rehabilitation are discussed.
\end{abstract}

Keywords: Marine mammal, Northern elephant seal (Mirounga angustirostris), kyphosis, thoracic vertebrae, Cobb angle.

\section{INTRODUCTION}

The population of Northern elephant seals (Mirounga angustirostris) has grown steadily in the past century, after being hunted to near extinction in the mid1800s (Bonnell et al 1974). The current population is thought to have returned to pre-near extinction numbers, estimated to be approximately 179,000 individuals (Carretta et al 2015). Stranded Northern elephant seal pups are a common occurrence on central California (CA) beaches in the spring months. The overwhelming majority of these pups are molted weanlings, many of whom have never learned to fish for themselves and are still surviving off fat stores from their mother's milk. The most common causes of stranding are malnutrition, Otostrongylus circumlitus infection, and Northern elephant seal skin disease (Colegrove et al 2005). There are over 32 institutions licensed to rehabilitate marine mammals under NOAA jurisdiction and over 120 participants to respond to stranded marine mammals as part of the marine mammal stranding network across the United States (US) (NMFS 2011).

Stranding due to congenital skeletal abnormalities in pinnipeds has not been published previously; however, vertebral inconsistencies have been identified among apparently healthy wild elephant seals (Anderson 2011). Kyphosis of the thoracic vertebrae can give an animal a 'humpback' appearance and complications from this spinal abnormality can be

\footnotetext{
Ms. Mulreany currently is a DVM candidate at the VirginiaMaryland College of Veterinary Medicine. She has a particular interest in avian medicine and conservation research.
}

variable. It is a common congenital condition of screw-tailed dogs due to a hemivertebrae, and most cases present nonclinical (Moissonnier et al 2011). In more severe cases of kyphosis in dogs, the angle abnormality results in spinal cord stenosis, leading to neurological impairment such as ataxia and pelvic limb paresis (Charalambous et al 2014). The Cobb angle has been used clinically to measure the angle of divergence of spinal deformities in both human and veterinary medicine and serves to categorize the degree of spinal abnormality into three levels of severity: mild ( $<15$ degrees), moderate (15-60 degrees), and severe (>60 degrees) (Aikawa et al 2007). Kyphosis of the thoracic vertebrae has not been documented previously in elephant seals, though there are known cases that have been rehabilitated and released by the Marine Mammal Center (personal communication 2015). This report describes the rehabilitation of a Northern elephant seal pup with kyphosis and the use of the Cobb angle to characterize the abnormality.

\section{CASE REPORT}

A $53.3 \mathrm{~kg}, 152 \mathrm{~cm}$ (117.26 lb, 60 in) male Northern elephant seal pup was found stranded on a beach in Malibu, CA in April 2015. The pup was brought to the California Wildlife Center for evaluation and rehabilitation. Intake procedures included physical exam and bloodwork. The pup had a palpable deformation of the thoracic vertebrae though was fully ambulatory. The pup appeared mildly dehydrated with a body condition score (BCS) of $2 / 5$, but physical examination was otherwise unremarkable. Chemistry analysis run on an Abaxis VS2 (Abaxis, Union City, CA) showed mild hypokalemia (blood potassium 4.6 $\mathrm{mmol} / \mathrm{L}$; reference range 4.7-6.1 $\mathrm{mmol} / \mathrm{L}$ [Dierauf and Gulland 2001]), but was otherwise normal. Complete blood cell count was run on an Abaxis HM5 and all values were within reference range.

The pup was put on a refeeding program that consisted of tube feeding a combination of electrolyte solution and fish gruel (outlined in Table 1). On day 
Table 1. Northern elephant seal feeding schedule.

\begin{tabular}{|c|c|c|}
\hline DAY & FEEDING SCHEDULE & FLUID/FOOD INTAKE \\
\hline Intake & \multicolumn{2}{|c|}{$100 \mathrm{ml}$ electrolyte solution (ES)* PO via orogastric tube (OT). } \\
\hline \multirow[t]{3}{*}{ Day 1} & AM Feed** & $\begin{array}{l}400 \mathrm{ml} \text { ES , } 40 \mathrm{ml} \text { kaopectate, } \\
468 \mathrm{mg} \text { potassium and } 1 \mathrm{Mazuri}{ }^{\circledast} \text { Vita-zu } \\
\text { mammal tablet PO via OT. } \\
1 \mathrm{ml} \text { B vitamin complex }{ }^{* * *} \text { IM }\end{array}$ \\
\hline & Noon Feed & $400 \mathrm{ml} \mathrm{ES}$ and $40 \mathrm{ml}$ kaopectate PO via OT \\
\hline & PM Feed** & $\begin{array}{l}400 \mathrm{ml} \mathrm{ES}, 40 \mathrm{ml} \text { kaopectate, and } 468 \mathrm{mg} \\
\text { potassium PO via OT }\end{array}$ \\
\hline \multirow[t]{3}{*}{ Day 2} & AM Feed & $\begin{array}{l}250 \mathrm{ml} \mathrm{ES}, 150 \mathrm{ml} \text { Lafeber }^{\circledR} \text { Emeraid } \\
\text { Piscivore (LEP), } 468 \mathrm{mg} \text { potassium and } 1 \\
\text { Mazuri } \text { Vita-zu mammal tablet PO via OT. } \\
1 \mathrm{ml} \text { B vitamin complex IM }\end{array}$ \\
\hline & Noon Feed & $\begin{array}{l}200 \mathrm{ml} \text { ES, } 200 \mathrm{ml} \mathrm{LEP}, 40 \mathrm{ml} \text { kaopectate } \\
\text { PO via OT }\end{array}$ \\
\hline & PM Feed & $\begin{array}{l}150 \mathrm{ml} \mathrm{ES}, 250 \mathrm{ml} \mathrm{LEP}, 40 \mathrm{ml} \text { kaopectate, } \\
\text { and } 468 \mathrm{mg} \text { potassium PO via OT }\end{array}$ \\
\hline Day 3 & \multicolumn{2}{|l|}{ Fasted for radiographs } \\
\hline Days $4-8$ & AM, Noon and PM feeds & $400 \mathrm{ml}$ gruel**** via OT \\
\hline Days 9-11 & AM, Noon and PM feeds & $\begin{array}{l}400 \mathrm{ml} \text { gruel PO via OT while gradually } \\
\text { introducing fish through assisted feedings }\end{array}$ \\
\hline Days $12-15$ & AM, Noon and PM feeds & $\begin{array}{l}200 \mathrm{ml} \text { water and } 200 \mathrm{ml} \text { gruel via OT, } 1 \mathrm{lb} \\
\text { herring handfed }\end{array}$ \\
\hline Days $16-19$ & AM, Noon and PM feeds & $\begin{array}{l}300 \mathrm{ml} \text { water and } 100 \mathrm{ml} \text { gruel via OT, } \\
1.5-2 \mathrm{lb} \text { herring handfed }\end{array}$ \\
\hline Days 20-22 & AM, Noon and PM feeds & $\begin{array}{l}300 \mathrm{ml} \text { water, } 2.5 \mathrm{lb} \text { of herring bottom } \\
\text { fed (BF) off a small pool }\end{array}$ \\
\hline Day 23 & AM, Noon and PM feeds & $2.5 \mathrm{lb}$ herring $\mathrm{BF}$ \\
\hline Days $24-35$ & AM, Noon and PM feeds & $3 \mathrm{lb}$ herring $B F$. \\
\hline
\end{tabular}

Electrolyte solution contains sodium, potassium, and bicarbonate.

** AM feeds are given at 9 AM, PM feeds are given at 4 PM.

*** Henry Schein ${ }^{\circledR}$ Vitamin B complex 150

**** Gruel contains a slurry of water, salt, potassium, bicarbonate, vitamin B1, Mazuri ${ }^{\circledast}$ Vita-Zu mammal tablets, fish oil, vegetable oil, and herring.
T1-T3 on radiographs of large animals (Harrison et al 2001; Briggs et al 2007). A regional Cobb angle was chosen as the method of measurement because endplates of the affected vertebrae were readily visualized, though the vertebral bodies of all affected vertebrae could not be determined, making the centroid and posterior tangent techniques problematic. The angle was measured between the intersection of parallel lines drawn from the cranial end plate of the most cranially affected vertebrae (T4) and the caudal end plate of the most caudally affected vertebrae (T6) (Figure 1).Using the regional Cobb angle technique, the curve of the kyphosis was measured to be 66.72 degrees. The kyphosis was considered severe given the angle measured was $>60$ degrees.

During the first 34 days of rehabilitation, the pup was kept dry docked in a pen with a colony of other Northern elephant seal pups that ranged from 10 to 15 individuals. Once the pup was stable enough to eat whole fish, he was fed in a shallow metal pool and allowed to bottom feed for fish.

On Day 34, the pup was moved to the prerelease pen with a large inground pool, $5 \times 10 \times 3 \mathrm{ft}, 1,100$ gallons $(3.05 \times 0.91 \times$ $1.52 \mathrm{~m}, 4,164$ l). There, he was housed with two other elephant seal pups. All three pups were fed together in the large pool. He was able to enter and exit the pool on his own and swam well, but was only turning to the right. His swimming was closely monitored for the ability to turn to the left. three of intake a lateral radiograph was taken (TR 90, MinXray, Northbrook, IL) and a marked kyphosis of the cranial thoracic vertebrae was apparent affecting T4-T6. There is possibly a hemivertebrae of the vertebral body of the pup's T5, though it is inconclusive. It was decided to further classify the degree of the abnormality using radiographic technique.

There are several methods for measurement of spinal deformities, the most common being the Cobb angle, the centroid angle, and the posterior tangent method. All three techniques have been shown to adequately measure angles of kyphosis with similar reliability. Regional measurements (measuring only thoracic vertebrae affected by the kyphosis) rather than global measurements (measuring all thoracic vertebrae) have been shown to be more reliable across all three measurement techniques. Additionally, global angles present a challenge, as often it is difficult to visualize

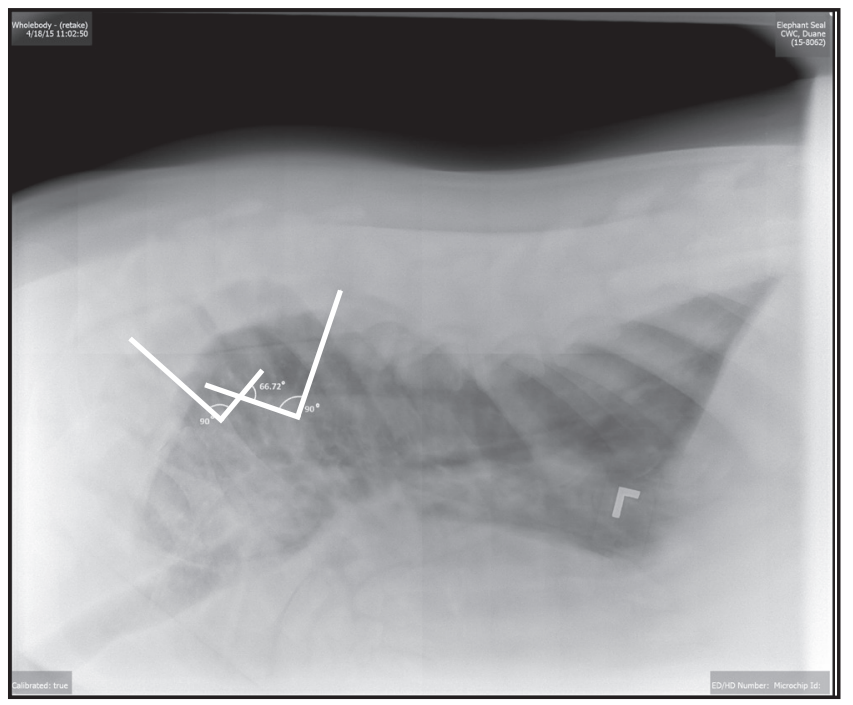

Figure 1. Lateral radiograph displaying the Cobb angle of T4-T6. 
On Day 45, it was observed that the pup could turn left, although had a preference for turning right. Requirements for release include a minimum weight of $50 \mathrm{~kg}$, ability to swim and dive in deep water, and ability to compete with other elephant seals for food. Once the pup met all of these requirements, he was scheduled to be released on Day 52. Though the pup still had a preference for turning right, he could swim and dive sufficiently. Upon exit exam, the kyphosis was less noticeable; however this was attributed to the improved BCS rather than any spinal remodeling. Follow up radiographs were not taken due to the difficulty in restraining the pup at his release weight. In-house bloodwork was repeated prior to release and was within normal limits. The pup was released at Nicholas Canyon beach in Malibu.

\section{DIscussion}

Though it is possible to have kyphosis in an animal as a result of traumatic injury, the more likely cause in this case was a congenital defect either of the spine or collagen. Vertebral body malformation (hemivertebrae) of the thoracic vertebrae has been documented to commonly cause a kyphosis in screw-tailed dogs such as French and English bulldogs. This is thought to be due to the normal presence of hemivertebrae in the coccygeal vertebrae, which results in the screw-tail appearance. Even a minor vertebral body malformation with repeated trauma has been shown to induce a kyphosis (Jeffery et al 2007). Severe kyphosis can cause neurological symptoms from spinal cord compression such as incontinence and paresis, however the range of clinical signs can vary from subclinical to debilitating (Jeffery et al 2007; Aikawa et al 2007).

It is difficult to extrapolate these findings in dogs to male Northern elephant seals whose weight can easily reach upwards of 2,268 $\mathrm{kg}(5,000 \mathrm{lb})$. The considerable force placed on the seal's spine due to its massive size was taken into consideration in the release of this animal. The top priorities were to release the pup with no clinical signs of pain and an ability to feed itself in the wild. During the entire course of rehabilitation, the pup never showed any ambulatory defects or other symptoms to indicate that he was in pain. When fed in a pool with conspecifics, the pup was able to compete adequately for the provided food and gained weight at a similar rate as his pen mates. This indicated to the staff that the pup most likely stranded due to malnutrition from lack of resources, like so many other marine mammal strandings, rather than due to his kyphosis, and subsequently was released.
Another important consideration was the reproductive success of this pup. Northern elephant seals are polygamous and alpha males need to rely heavily on their body condition to be able to compete with other males for mates (Crocker et al 2012). Though not ideal, it was assumed that if the abnormality had any serious physical implications on the pup, he would not be physically fit enough to compete for mates and therefore would not pass on any congenital defects that may have contributed to his condition.

While the pup was able to swim sufficiently within the rehabilitation pool on site, it is impossible to know the success of released animals with spinal deformities without the use of satellite tracking data. Currently, satellite tracking is cost prohibitive for most rehabilitation programs, ranging from $\$ 7,000$ to $\$ 9,000$ per animal per year (Thomas et al 2011), though their use would be invaluable for documentation of success rates for released wildlife.

Marine mammal veterinarians have limited references available regarding anatomical abnormalities seen within wild pinniped populations. To the knowledge of the author, there is no published case of kyphosis in an elephant seal. Research on elephant seals has far reaching implications as they often serve as the model for many pinniped species' medical care and rehabilitation, most notably the endangered Hawaiian monk seal (Monachus schauinslandi) (Harting et al 2007).

\section{CONCLUSION}

With supportive care and time, stranded elephant seal pups with even a severe kyphosis may be rehabilitated and released. Documentation of such cases with measurement of the degree of kyphosis can assist the marine mammal veterinary community in assessing future cases of pinniped spinal deformations. Improvements in satellite tracking availability and cost would allow for following the success of these cases long-term.

\section{ACKNOWLEDGEMENTS}

The author gratefully acknowledges the California Wildlife Center and Duane Tom, DVM and Lorraine Barbosa, DVM for their excellent direction in the writing of this report.

\section{LITERATURE CITED}

Aikawa, T., et al. 2007. Vertebral Stabilization Using Positively Threaded Profile Pins and Polymethylmethacrylate with or Without Laminectomy, for Spinal Canal Stenosis and Vertebral Instability Caused by Congenital Thoracic Vertebral Anomalies. Veterinary Surgery. 36(5): 432-441. 
Anderson, C. E. Northern Elephant Seal (Mirounga angustirostris) Lumbar Spine: Normal Radiographic Anatomy and Common Radiographic Anomalies. IAAAM Conference Proceedings. Mirage Hotel and Casino, Las Vegas, NV. May 7-11, 2011.

Bonnell, M. L. and R. K. Selander. 1974. Elephant Seals: Genetic Variation and Near Extinction. Science. 184(4139): 908-909.

Briggs, A. M., T. V. Wrigley, E. A. Tully, P. E. Adams, A. M. Greig, and K. L. Bennell. 2007. Radiographic Measures of Thoracic Kyphosis in Osteoporosis: Cobb and Vertebral Centroid Angles. Skeletal Radiology. 36: 761-767.

Carretta, J. V., E. M. Oleson, J. Baker, D. W. Weller, A. R. Lang, K. A. Forney, M. M. Muto, B. Hanson, A. J. Orr, H. Huber, M. S. Lowry, J. Barlow, J. E. Moore, D. Lynch, L. Carswell, and R. L. Brownell. 2015. U.S. Pacific Marine Mammal Stock Assessments: 2015. [Memorandum]. National Oceanic and Atmospheric Administration: USA.
Charalambous, M., N. D. Jeffery, P. M. Smith, R. Goncalves, A. Barker, G. Hayes, E. Ives, and A. E. Vanhaesebrouck. 2014. Surgical Treatment of Dorsal Hemivertebrae Associated with Kyphosis by Spinal Segmental Stabilization, with or Without Decompression. The Veterinary Journal. 202(2): 267-273.

Colegrove, K. M., D. J. Greig, and F. M. D. Gulland. 2005. Causes of Live Strandings of Northern Elephant Seals (Mirounga angustirostris) and Pacific Harbor Seals (Phoca virulina) along the Central California Coast, 1992-2001. Aquatic Mammals. 41(1): $1-10$.

Crocker, D. E., D. S. Houser, and P. M. Webb. 2012. Impact of Body Reserves on Energy Expenditure, Water Flux, and Mating Success in Breeding Male Northern Elephant Seals. Physiological and Biochemical Zoology: Ecological and Evolutionary Approaches. 85(1): 11-20.

Dierauf, L. A. and F. M. D. Gulland. 2001. CRC Handbook of Marine Mammal Medicine, 2nd edition. CRC Press: Boca Raton, FL.

\section{Do you have a dedicated volunteer or critter-sitter? Thank them for their hard work with a membership to NWRA!}

For more information, please go to our website, WWW.NWRAwildlife.org, and click on Join NWRA.

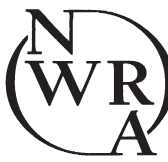

National

WildLIFE REHABILITATORS

Association 
Harrison, D. E., R. Cailliet, D. D. Harrison, T. J. Janik, and B. Holland. 2001. Reliability of Centroid, Cobb and Harrison Posterior Tangent Methods: Which to Choose for Analysis of Thoracic Kyphosis. Spine. 26(11): 227-234.

Harting, A. L., J. D. Baker, and T. C. Johanos. 2007.

Reproductive Patterns of the Hawaiian Monk Seal. Marine Mammal Science. 23(3): 553-573.

Jeffery, N. D., P. M. Smith, and C. E. Talbot. 2007. Imaging Findings and Surgical Treatment of Hemivertebrae in Three Dogs. Journal of the American Veterinary Medical Association. 230(4): 532-536.
Moissonnier, P., P. Gossot, and S. Scotti. 2011.

Thoracic Kyphosis Associated with Hemivertebrae. Veterinary Surgery. 40(8): 1029-1032.

NMFS. National Marine Fisheries Service [website]. 2011. FAQs: Whale, Dolphin, Seal and Sea Lion (Marine Mammal) Strandings. [cited 2011 June 28] Available from: <http://www.nmfs.noaa.gov/ $\mathrm{pr} /$ health/faq.htm $>$.

Thomas, B., J. D. Holland, and E. O. Minot. 2011. Wildlife Tracking Technology Options and Cost Considerations. Wildlife Research. 38(8): 653-663. (ivg

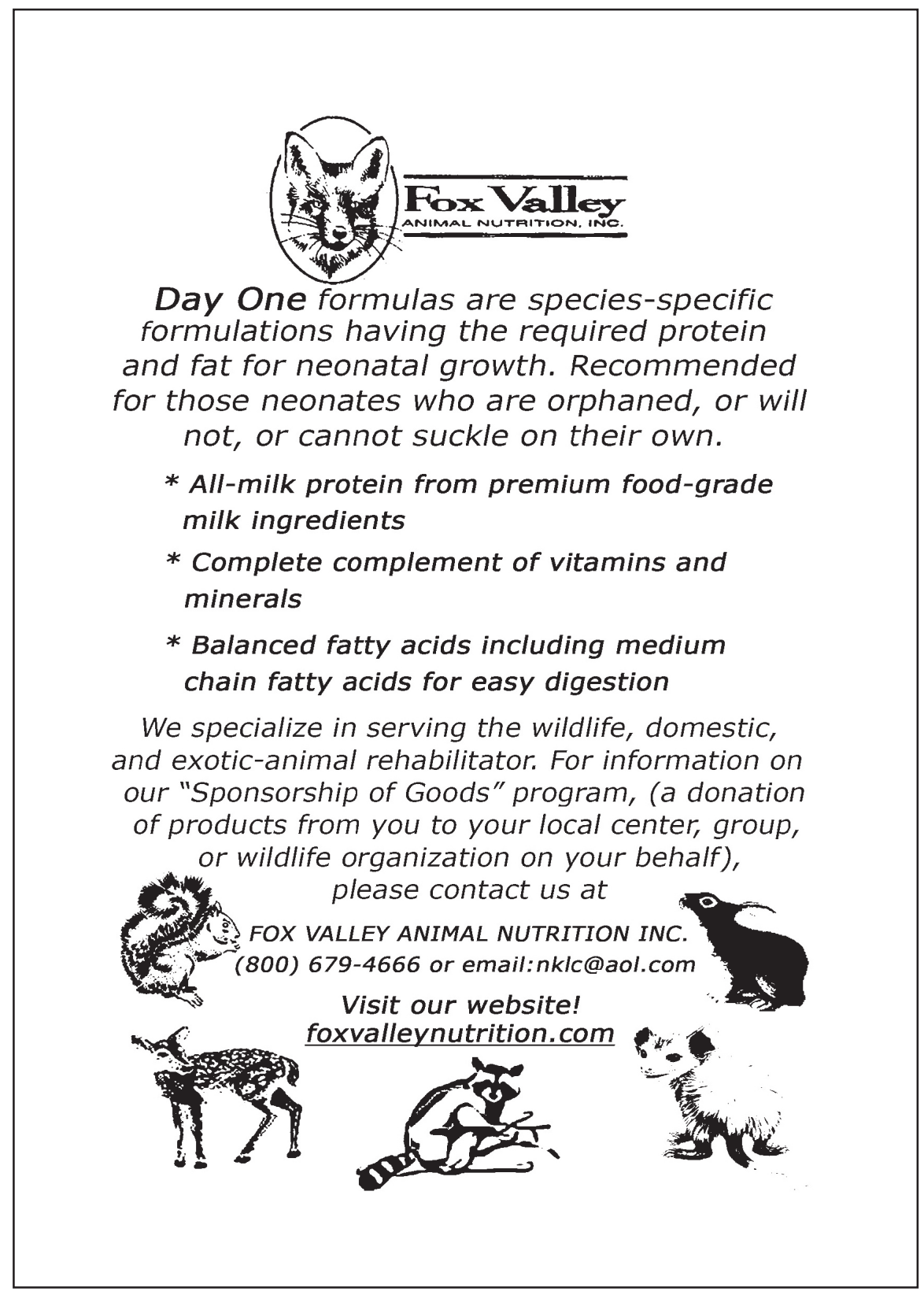

